\title{
The influence of general health status and social support on symptomatic outcome following coronary artery bypass grafting
}

\author{
G M Lindsay, L N Smith, P Hanlon, D J Wheatley
}

\begin{abstract}
Objectives-To assess health status, level of social support, and presence of coronary artery disease risk factors before and after coronary artery bypass grafting (CABG); to assess symptomatic relief approximately 12 months postoperatively; and to examine the association between preoperative health status and recurrence of symptoms.

Design-Observational study.

Setting-Preoperatively, in hospital outpatient department (1995-1996); postoperatively, at home (1996-97).

Subjects and methods-Patients awaiting elective CABG were recruited one month before the expected date of operation. Preoperative assessment included severity of symptoms, coronary artery disease risk factors, short form 36 (SF-36) questionnaire, and social activities questionnaire. The presence and severity of angina and breathlessness were reported postoperatively (mean 16.4 months). Multiple regression analysis was used to identify factors associated with improved outcome following CABG.

Main outcome measure-Patient reported presence and severity of angina and breathlessness. Results-183 patients were followed for a mean of 16.4 months after CABG. Angina and breathlessness were completely relieved in $55 \%$ and $36 \%$ of patients, respectively. In patients with residual symptoms, the severity was significantly reduced (angina $\mathrm{p}<0.001$; breathlessness, $p=0.02)$. Patients with low SF-36 scores and low social network scores preoperatively were less likely to be relieved of symptoms $(\mathrm{p}<0.001)$. Health status and social support levels preoperatively were lower than in other reported coronary artery disease patients groups. Preoperatively, coronary artery disease risk factors were higher than recommended in current guidelines: $67.4 \%$ had raised plasma cholesterol, $39.0 \%$ were hypertensive, $80 \%$ were moderately obese, and $22.9 \%$ were smokers.
\end{abstract}

Conclusions-Recurrence of symptoms exceeded other published studies. Patients' perception of general health, symptoms, and social support influences outcome.

(Heart 2001;85:80-86)

Keywords: health status indicator; coronary artery bypass; social support; risk factors

Nursing and Midwifery School, University of Glasgow, 68 Oakfield Avenue, Glasgow G12 8LS, UK G M Lindsay

L N Smith

Department of Public Health, University of Glasgow, 1 Lilybank Gardens, Glasgow G12 8LS, UK

P Hanlon

University

Department of

Cardiac Surgery,

North Glasgow

University NHS Trust,

10 Alexandra Parade,

Glasgow G4 0SF, UK

D J Wheatley

Correspondence to:

Dr Lindsay

GL1Z@clinmed.gla.ac.uk

Accepted 6 September 2000
Coronary artery bypass graft (CABG) surgery has been an accepted treatment for angina pectoris for more than 25 years. ${ }^{12}$ Models have been developed that use preoperative information (for example, severity of coronary artery disease; previous CABG; degree of comorbidity) to stratify surgical risk and predict the prognosis following CABG. ${ }^{34}$ Models differ with respect to the range of data included and their source (for example, medical records, angiogram results, computerised patient information systems). Although increasing interest in the influence of patient health and wellbeing on outcome following healthcare interventions has been reported, patients' perspective of their health status has not been a component of models designed to predict prognosis. General health status as perceived by the patient may influence outcome following CABG surgery.

A range of health measurement tools has been developed over the last decade for the purpose of quantifying and differentiating between different health states. ${ }^{6}$ One validated health status measure that has been used extensively is the short form 36 (SF-36). ${ }^{78}$ This is a general health status measure that has been used to evaluate health status in general population surveys ${ }^{9}$ and in the presence of coronary artery disease, ${ }^{7}$ and to determine the effectiveness of medical treatments in patients with angina. ${ }^{10}$

Social support is increasingly recognised as an important aspect of life that relates to positive health. ${ }^{112}$ In a systematic review of studies investigating aspects of social support, a positive relation between increased social support and a lower incidence of coronary artery disease was found. ${ }^{13}$ In that study, social support was considered to be a function of an increased number of social contacts and the quality of those relations, including emotional and confiding support. In the present study, using the SF-36 instrument, we related the patients' perceived health status preoperatively, their levels of social support, demographic indices, and the presence of preoperative coronary artery disease risk factors to the recurrence and severity of symptoms following CABG.

\section{Methods}

PATIENTS

A consecutive sample of patients $(n=214)$ was recruited over a six month period from the 
surgical waiting list for $\mathrm{CABG}$ at one cardiac surgical centre, according to the following inclusion criteria:

- isolated CABG procedure;

- elective operation;

- residence within approximately 50 miles of the hospital;

- expected date for operation estimated to be approximately four weeks after preoperative assessment for the study.

All patients invited to participate in the study agreed to take part, and written informed consent was provided. The sample size was set at 214 in order to allow sufficient statistical power to detect a $10 \%$ change in the SF-36 scores with a confidence level of $90 \%$ and a probability value of $p=0.05$. Ethical approval was obtained from the research ethics committee of Glasgow Royal Infirmary University NHS (National Health Service) Trust.

ASSESSMENT INSTRUMENTS

Three instruments - the SF- $36,{ }^{7}$ the social networks assessment, ${ }^{14}$ and a visual analogue scale to assess severity of angina and breathlessness ${ }^{15}$ - were completed by the patients.

The SF-36 health assessment questionnaire has been reported as valid and reliable in normal populations as well as in coronary artery disease patient groups. ${ }^{79}$. It has been found to be an acceptable health status measure for use within the NHS. ${ }^{16}$ The SF-36 form is a 36 item scale that generates scores for eight dimensions of health. These are: physical functioning, mental health, bodily pain, general health, vitality (energy/fatigue), social functioning, role limitations because of physical problems, and role limitations because of mental health problems (psychological distress and psychological wellbeing). The scores for each domain are based on the same scale of 0 to 100 ; 0 is the worst possible health status and 100 the best.

The social activities questionnaire was developed as a measure of social wellbeing, including number and type of social contacts together with perceived satisfaction and value of interpersonal relationships. ${ }^{14}{ }^{17}$ It consists of 11 questions covering the number of friends and family the patient has, how much they feel at ease and "get along" with those contacts, and how often they meet. In addition, membership and level of activity in clubs, groups, or voluntary organisations were explored. Scores are calculated from the responses, with higher scores being associated with a greater level of social support. The possible scores range from a minimum of 8 to a maximum of 50 .

The visual analogue scale ${ }^{15}$ consists of a horizontal continuous line ranging from 0 to 7 , where 0 represents "no effect on overall wellbeing and health" and 7 represents "complete disability, discomfort and restriction to life". Respondents were asked to indicate the severity of their symptoms at the time of data collection by placing a mark on the scale. A similar scale design has been used in postoperative pain assessment. ${ }^{18}$
DATA COLLECTION PROCESS

Patients were assessed twice: first before their operation (approximately four weeks before) in the outpatient department, and second at approximately 16 months after their operation in their home. The self completion instruments were posted to participants before both assessment appointments. All data were collected by the same researcher.

PREOPERATIVE CLINICAL ASSESSMENT

Demographic details (age, sex, postcode) were used to estimate socioeconomic status, using an updated version of the Carstairs and Morris deprivation scores. ${ }^{19}$ Tobacco smoking habit was recorded. Blood pressure was measured in accordance with the British Hypertension Society guidelines. ${ }^{20}$ Plasma cholesterol was measured from a venous blood sample at the Institute of Biochemistry, Glasgow Royal Infirmary NHS Trust, using standardised protocols and internationally agreed quality assurance procedures. The patients were weighed in light clothes without shoes to the nearest $0.1 \mathrm{~kg}$ and height was measured in $\mathrm{cm}$ to the nearest $0.5 \mathrm{~cm}$. Body mass index $\left(\mathrm{kg} / \mathrm{m}^{2}\right)$ was derived from these measurements. Waist measurement with a flexible tape was taken as the smallest circumference between the rib cage and the iliac crest and recorded to the nearest $0.1 \mathrm{~cm}^{21}$

\section{POSTOPERATIVE ASSESSMENT}

The number of grafts inserted at operation was noted from the patients' medical records. Patients were asked to document whether angina or breathlessness or both were experienced. When present, the severity was reported as previously described for the preoperative assessment.

\section{STATISTICAL METHODS}

Summary statistics were calculated for the variables recorded in both preoperative and postoperative assessments. The MannWhitney test and Student's $t$ test were used to compare the presurgery variables and the number of grafts inserted at operation in patients who were relieved of angina and breathlessness and in those who continued to experience symptoms. In addition, a comparison was made between demographic characteristics of our study patients and all patients in the local health board area undergoing CABG over the same time period (J Womersley, Greater Glasgow Health Board, personal communication, 1997), and from the UK cardiac surgical register. ${ }^{22}$ The influence of coronary artery disease risk factors, socioeconomic status, health status (SF-36), severity of angina and breathlessness, and social networks on presence of symptoms postoperatively was assessed using multiple linear regression analysis. $^{23}$

\section{Results}

DEMOGRAPHICS

Table 1 shows the patient demographics, including age, sex ratio, and distribution according to socioeconomic deprivation categories, as measured by the Carstairs classifi- 
Table 1 Patient demographics

\begin{tabular}{|c|c|c|c|c|c|c|c|}
\hline \multirow{3}{*}{$\begin{array}{l}\text { Age (years) (mean (SD)) } \\
\text { Sex } \\
\text { Deprivation category }\end{array}$} & \multicolumn{7}{|c|}{$58.2(7.7)$, range 39.9 to 79.3} \\
\hline & \multicolumn{3}{|c|}{ Male $170(79.4 \%)$} & \multicolumn{4}{|c|}{ Female $44(20.6 \%)$} \\
\hline & I & II & III & IV & $\mathrm{V}$ & VI & VII \\
\hline & 3.3 & 5.6 & 20.6 & 18.2 & 13.6 & 16.4 & 22.4 \\
\hline
\end{tabular}

${ }^{\star}$ From McLoone. ${ }^{19}$

Table 2 Mean values of major coronary artery disease risk factors, with target levels at preoperative assessment

\begin{tabular}{lll}
\hline Risk factor & Mean $(S D)$ & Per cent exceeding \\
\hline Systolic blood pressure $(>140 \mathrm{~mm} \mathrm{Hg})$ & $134.7(10.1)$ & 39.0 \\
Diastolic blood pressure $(>90 \mathrm{~mm} \mathrm{Hg})$ & $81.0(12.3)$ & 30.0 \\
Total cholesterol $(>5.2 \mathrm{mmol} / \mathrm{l})$ & $5.8(1.2)$ & 67.4 \\
Body mass index $\left(>25 \mathrm{~kg} / \mathrm{m}^{2}\right)$ & $28.0(3.4)$ & 80.8 \\
Body mass index $\left(>30 \mathrm{~kg} / \mathrm{m}^{2}\right)$ & $28.0(3.4)$ & 22.9 \\
Waist, female $(<80 \mathrm{~cm})$ & $91.0(9.2)$ & 69.2 \\
Waist, male $(<94 \mathrm{~cm})$ & $96.9(8.1)$ & 36.9 \\
& & Per cent present \\
Diabetes mellitus & & 22.6 \\
Current smoking & & 2.9 \\
\hline
\end{tabular}

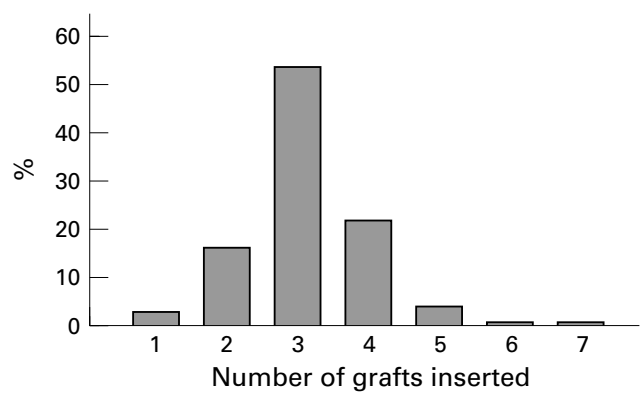

Figure 1 Breakdown (\%) of the numbers of grafts inserted at coronary artery bypass grafting in the study patients.

cation. ${ }^{19}$ The patients in the study were younger (mean age 58.2 v 60.7 years, $\mathrm{p}<0.001$ ) and were from areas of higher socioeconomic deprivation $(\mathrm{p}<0.001)$ compared with all patients in the health board area undergoing CABG during the same time period, but had a similar sex ratio. Comparisons with the UK CABG population of 21568 patients undergoing CABG surgery during $1995 / 6^{23}$ also confirm the similar sex ratio, but patients in the present series were younger (58.2 $v 60.6$ years, $\mathrm{p}<0.001)$.

PREOPERATIVE CORONARY ARTERY DISEASE RISK FACTORS

In table 2 the percentage of patients with coronary artery disease risk factors above target levels, together with mean and standard deviations for continuous variables (normally
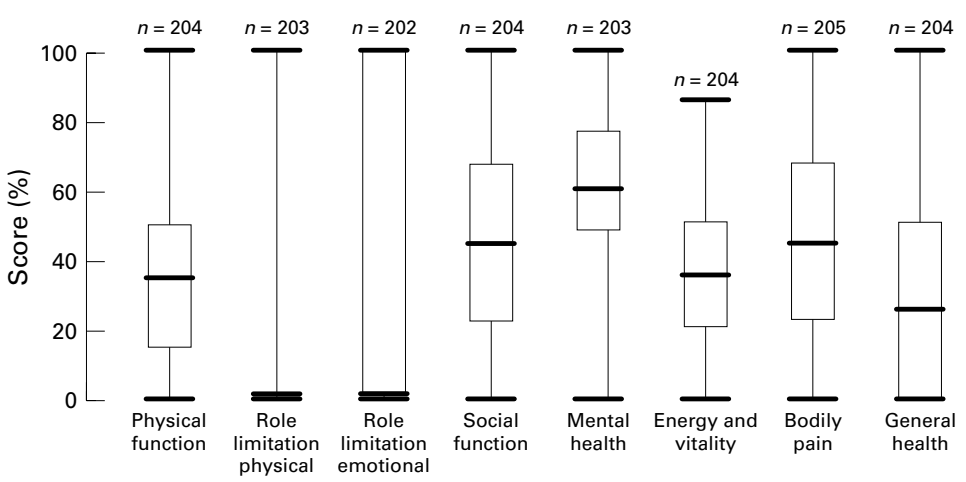

Figure 2 Box and whisker plot of SF-36 health survey scores for the eight health domains, showing median, interquartile range, and total range of scores. distributed data) and percentages for categorical variables are presented. A large number of the patients had coronary artery disease risk factors exceeding target levels associated with lowest risk of subsequent coronary events.

NUMBER OF GRAFTS INSERTED AT OPERATION

From one to seven grafts were inserted during the operation; the relative percentages are given in fig 1 .

SF-36 HEALTH STATUS

Scores were calculated for the eight domains of health. The median, interquartile range, and total range of scores are presented in fig 2 . The mean scores and their standard deviations are presented in table 3 and indicate that physical role limitation was the lowest scored health domain, while mental health was the highest scored or least affected health domain. Comparison with results obtained in other published surveys is also presented in table 3 . The patients in this study had lower scores across all domains of health, indicating poorer health status. Because the "role limitation: physical" and "role limitation: emotional" domains were not normally distributed (fig 2), comparison with mean values from the other series presented was not possible.

SOCIAL NETWORK SCORES

The social network scores were calculated from the questionnaire responses returned by the majority of the study group $(86.1 \% ; n=179)$. The mean (SD) of scores was 24 (7.0) (range 8 to 38). The mean scores were lower than reported in a large survey of the general population $(n=4351)$ in the USA, where the mean (SD) was 25.8 (7.9).$^{13}$ It was not possible with the data available to check whether this observed difference was significant.

\section{ATTRITION AND SURVIVAL RATE}

The number of original study patients $(\mathrm{n}=214)$ who underwent the CABG operation was $209(97.7 \%)$. Five patients $(2.4 \%)$ did not have an operation for various reasons, namely: improvement in clinical status $(n=1)$, surgical risk subsequently considered too high $(n=1)$, patient refused operation $(n=2)$, patient not contacted with date for operation because of misplaced medical records $(n=1)$. Thirty day postoperative mortality was $4.8 \%$ $(\mathrm{n}=10)$.

From a total of 199 patients who survived beyond the 30 day perioperative period, 13 patients refused follow up assessment and three died (two male, one female) during the first year after operation. Thereafter 183 patients, representing $85.5 \%$ of the original cohort ( $\mathrm{n}=214)$, were followed up completely. Overall one year survival for those who were operated on ( $n=209)$ was $93.08 \%$. Postoperative assessment was undertaken after a mean interval of 16.4 months.

ANGINA AND BREATHLESSNESS

Almost all of the patients reported angina $(94.2 \%)$ and breathlessness $(92.8 \%)$ at preoperative assessment. At postoperative assess- 
Table 3 SF-36 domain scores for study patients, general population sample, and two groups of patients with coronary artery disease

\begin{tabular}{|c|c|c|c|c|c|}
\hline $\begin{array}{l}\text { SF-36 domain scores } \\
(0-100 \%)\end{array}$ & Study patients & $\begin{array}{l}\text { General populationt: } \\
\text { female 55-64 years }\end{array}$ & $\begin{array}{l}\text { General populationt: } \\
\text { male 55-64 years }\end{array}$ & $\begin{array}{l}\text { Recent myocardial } \\
\text { infarction }\end{array}$ & Recent angina ${ }^{\star}$ \\
\hline $\mathrm{n}$ & 214 & $684-779$ & $681-729$ & 107 & 256 \\
\hline Bodily pain & $44.1(25.9)$ & $75.0(25.1)$ & $78.8(23.6)$ & $72.8(25.3)$ & $61.6(24.5)$ \\
\hline Energy, vitality & $35.6(21.1)$ & $59.0(21.4)$ & $62.9(22.7)$ & $57.7(19.0)$ & $48.5(20.3)$ \\
\hline General health & $36.9(17.1)$ & $68.0(22.0)$ & $68.1(22.9)$ & $59.2(19.3)$ & $52.0(18.9)$ \\
\hline Mental health & $61.1(18.7)$ & $74.4(18.5)$ & $78.0(17.3)$ & $75.8(15.7)$ & $73.0(18.7)$ \\
\hline Physical function & $34.8(24.1)$ & $74.8(23.5)$ & $80.0(22.1)$ & $69.7(26.1)$ & $63.2(26.7)$ \\
\hline Role: emotional & $\ddagger$ & $83.3(32.5)$ & $85.8(29.9)$ & $73.5(38.0)$ & $70.2(36.6)$ \\
\hline Role: physical & $\ddagger$ & $76.6(36.9)$ & $78.8(36.1)$ & $51.4(39.4)$ & $44.2(39.0)$ \\
\hline Social function & $47.8(28.3)$ & $85.9(22.6)$ & $86.9(22.6)$ & $84.6(21.2)$ & $80.3(23.0)$ \\
\hline
\end{tabular}

Values are mean (SD).

${ }^{\star}$ See SF-36: health survey manual and interpretation guide. ${ }^{7}$

+See Jenkinson et al. ${ }^{9}$

$\ddagger$ See text and fig 2 .

ment, $45.1 \%$ of patients reported angina, although the mean self rated score was reduced from that reported preoperatively (4.2 $v 2.8$, $\mathrm{p}<0.001)$. Breathlessness was reported by $63.7 \%$ of patients postoperatively, but again the mean self rated score was reduced (4.0 $v$ 3.5, $\mathrm{p}=0.021$ ).

Differences in the preoperative variables for patients with and without angina or breathlessness are presented in table 4. Patients who reported angina were more likely to be younger $(\mathrm{p}<0.008)$ and to have lower health status, as measured by the physical function $(\mathrm{p}=0.029)$, energy and vitality $(\mathrm{p}=0.002)$, bodily pain $(p=0.001)$, mental health $(p=0.001)$, and social function scales $(\mathrm{p}=0.009)$ of the SF-36 questionnaire. Patients who reported breathlessness were also more likely to be younger $(\mathrm{p}=0.023)$, to be current smokers $(\mathrm{p}=0.043)$, to have lower social network scores $(p=0.003)$, to have increased waist circumference $(p=0.027)$, and to have suffered lower levels of health preoperatively on the SF-36 scales for physical function $(p=0.067)$, energy and vitality $(p=0.027)$, mental health $(p=0.003)$, and role limitation because of physical factors $(p=0.020)$.

The contribution of preoperative variables to the presence of angina and breathlessness postoperatively was examined using a multiple linear regression model. Increased age and lower score in bodily pain (SF-36) (that is, more preoperative general pain) were associated with recurrence of angina $\left(R_{\text {adjusted }}^{2}=12.5 \%\right)$. Postoperative breathlessness was associated with a lower social networks score, diabetes mellitus, and a lower score in mental health (SF-36) $\left(R_{\text {adjusted }}^{2}=12.1 \%\right)$.

\section{Discussion}

Our aims in this study were to report on the patients' own assessment of their general health, social support networks, and prevalence of uncorrected coronary artery disease risk factors before CABG, and to investigate any relation between such factors and the presence of angina and breathlessness approximately one year later.

\section{HEALTH STATUS}

Health status was measured by the SF-36 questionnaire and generated scores that were lower than scores from patients after myocardial infarction, from patients with angina, and from the general healthy population ${ }^{79}$ (table 3). Most of the study patients' scores were reduced by $45-55 \%$ compared with the scores obtained in the healthy population sample, with the exception of the mental health domain where the smallest difference $(17 \%)$ was observed. As there was not a notable difference

Table 4 Differences in preoperative variables between patients with and without angina and breathlessness more than one year after surgery

\begin{tabular}{|c|c|c|c|c|c|c|}
\hline \multirow[b]{2}{*}{ Preoperative variables } & \multicolumn{3}{|c|}{ Angina postoperation } & \multicolumn{3}{|c|}{ Breathlessness postoperation } \\
\hline & Present & Absent & $p$ Value & Present & Absent & $p$ Value \\
\hline Age (years) & $57.1(8.4)$ & $59.1(6.6)$ & 0.008 & $59.9(6.5)$ & $57.2(7.9)$ & 0.023 \\
\hline Preoperative angina rating & $4.18(1.77)$ & $4.28(1.74)$ & 0.704 & $4.29(1.71)$ & $4.13(1.82)$ & 0.554 \\
\hline Preoperative breathlessness rating & $3.79(2.03)$ & $3.97(1.80)$ & 0.516 & $4.03(1.96)$ & $3.65(1.79)$ & 0.200 \\
\hline Sex (male/female) & $43.6(57.5)$ & $56.4(48.5)$ & 0.411 & $61.1(75.8)$ & $38.9(24.2)$ & 0.113 \\
\hline Deprivation category & $4.68(1.78)$ & $4.71(1.63)$ & 0.915 & $4.78(1.67)$ & $4.53(1.77)$ & 0.336 \\
\hline Social network score & $23.3(7.4)$ & $24.8(6.3)$ & 0.167 & $23.0(7.0)$ & $26.2(6.1)$ & 0.003 \\
\hline Current smoker (not current smoker) $(\%)$ & $48.8(43.9)$ & $51.2(56.1)$ & 0.570 & $0.26(0.44)$ & $0.22(0.44)$ & 0.043 \\
\hline Hypertension, systolic (yes/no) (\%) & $37.5(47.3)$ & $62.5(52.7)$ & 0.243 & $56.3(66.4)$ & $43.8(33.6)$ & 0.212 \\
\hline Hypertension, diastolic (yes/no) (\%) & $55.9(42.1)$ & $44.1(57.9)$ & 0.146 & $64.7(63.4)$ & $35.3(36.6)$ & 0.891 \\
\hline Hyperlipidaemia (yes/no) (\%) & $35.8(56.6)$ & $64.2(43.4)$ & 0.013 & $61.3(64.2)$ & $38.7(35.8)$ & 0.729 \\
\hline Obesity $($ BMI $>30)$ & $47.6(44.3)$ & $52.4(55.7)$ & 0.704 & $66.7(62.9)$ & $33.3(37.1)$ & 0.653 \\
\hline Increased waist circumference & $52.4(41.2)$ & $47.6(58.8)$ & 0.149 & $74.6(58.0)$ & $25.4(42.0)$ & 0.027 \\
\hline Diabetes mellitus (yes/no) (\%) & $47.8(44.7)$ & $52.2(55.3)$ & 0.776 & $65.2(63.5)$ & $34.8(36.5)$ & 0.01 \\
\hline SF-36 physical function & $31.8(23.7)$ & $39.8(23.6)$ & 0.029 & $33.6(22.5)$ & $40.6(25.7)$ & 0.067 \\
\hline SF-36 general health & $36.8(17.4)$ & $37.1(16.8)$ & 0.907 & $35.8(17.0)$ & $38.9(17.4)$ & 0.252 \\
\hline SF-36 energy/vitality & $31.6(20.7)$ & $41.4(19.4)$ & 0.002 & $34.3(20.0)$ & $41.5(20.9)$ & 0.027 \\
\hline SF- 36 bodily pain & $38.1(23.4)$ & $50.7(26.2)$ & 0.001 & $43.5(26.1)$ & $47.6(25.0)$ & 0.315 \\
\hline SF-36 mental health & $56.5(19.0)$ & $65.5(17.3)$ & 0.001 & $56.5(18.2)$ & $67.0(18.1)$ & 0.003 \\
\hline SF-36 social function & $44.1(28.0)$ & $55.1(26.4)$ & 0.009 & $49.2(28.5)$ & $51.5(26.1)$ & 0.598 \\
\hline SF-36 role limitation physical & $13.8(30.9)$ & $16.5(32.3)$ & 0.577 & $11.0(26.7)$ & $22.6(37.8)$ & 0.020 \\
\hline SF-36 role limitation emotional & $34.6(44.4)$ & $42.4(43.8)$ & 0.252 & $34.7(42.8)$ & $46.0(45.8)$ & 0.105 \\
\hline
\end{tabular}

Values are mean (SD) unless otherwise stated.

Significant $\mathrm{p}$ values are highlighted in bold font (Mann-Whitney $\mathrm{U}$ test). 
in the published scores for patients with recent myocardial infarction or angina and the general population group, our patients' scores are therefore similarly lower than the published data for coronary heart disease groups. This is not unexpected, given that these patients had been referred for operation. In addition, there are many other variables that are not matched in the groups-for example, age, sex ratio, and socioeconomic deprivation category could not be controlled. Because the data are not standardised, interpretation of results must be undertaken with caution. We do, however, consider that they provide a broad context in which the results from our study may be interpreted. Examination of other published series provided a general view of the variation in scores that can be obtained using this instrument. This is the first time that these indices have been used in a predictive model for postoperative symptoms.

SOCIAL SUPPORT NETWORKS

Social support networks were less strong than in other population groups, ${ }^{13}$ a factor that has been related to increased incidence of coronary artery disease morbidity and mortality ${ }^{24} 25$ and may reflect the adverse family history. The influence of the level of social support on the symptomatic outcome following CABG indicated that patients were more likely to have breathlessness after operation if levels of social support were low before operation (table 4). Improvements in the perception of general health and wellbeing following CABG have been reported in patients where self esteem has been enhanced through social contacts. ${ }^{26}$ This may be an area where interventions to promote and foster supportive social contacts could be beneficial to patients' health generally and to their postoperative outcomes. This view is supported by a study in which improved social support to patients following myocardial infarction was associated with a decrease in cardiac death or reinfarction. ${ }^{27}$ Cardiac rehabilitation provides a social context through which coronary prevention interventions are delivered, and it may be worthwhile to ensure that patients awaiting CABG are included in such programmes.

CORONARY ARTERY DISEASE RISK FACTORS

Raised plasma cholesterol, hypertension, and obesity were common (table 2), although this was not shown to have any influence postoperatively on the occurrence of angina and breathlessness or on their severity. The influence of these factors on native or graft vessel atherogenesis takes longer than the study period. ${ }^{28}{ }^{29}$ Also reduction in further coronary artery disease events, including death, over a 10 year period can be improved through achievement of levels of coronary artery disease risk factors below those measured in the participants in the present study. ${ }^{30}$ The influence of continued smoking upon recurrence of angina was not assessed in this study, although analysis was tied to preoperative smoking habit.

Socioeconomic deprivation category was not related to the presence of either angina or breathlessness postoperatively. This may be because the patient group was not drawn evenly from all groups to allow sufficient numbers for comparison. The patients were drawn largely from the east end of Glasgow and were from areas of worse socioeconomic deprivation $^{19}$ than all patients undergoing CABG surgery from the local health board area. In addition, they appeared to be significantly younger. Coronary event rates in individuals with coronary artery disease from areas of high socioeconomic deprivation are increased significantly compared with those in individuals from less deprived areas. ${ }^{312}$ Therefore the patients in this study had an age profile and socioeconomic deprivation status that confer a higher risk of adverse outcome. The extent to which the results from this study can be generalised should take into account the age and socioeconomic profile of the patients.

ANGINA AND BREATHLESSNESS

There was a trend for patients with high scores in the SF-36 domains of bodily pain, energy and vitality, mental health, and social function to have their angina relieved as a result of CABG surgery, as indicated in table 4 . Elimination of angina was enhanced further if their baseline physical function score was also high, but interestingly no other factors appeared to have a significant impact on the elimination or amelioration of angina symptoms at the postoperative assessment. This contrasts with the work of Pocock and colleagues, ${ }^{33}$ who showed that high levels of angina before operation were related to return of angina postoperatively. Low physical function scores on the SF-36 have been shown to be independently associated with mortality following $\mathrm{CABG} .{ }^{34}$

Fewer patients reported relief of angina than in other studies. However, we found that, despite residual symptoms, there was a significant improvement across all eight domains of the postoperative SF-36 scores $(p<0.001) .^{35}$ Pocock and colleagues detected chest pain at one year in $10 \%$ of patients, ${ }^{33}$ and CABRI trial (coronary angioplasty $v$ bypass revascularisation investigation) participants had $10.9 \%$ recurrence of angina. ${ }^{36}$ At two years $42 \%$ of patients may have recurrent angina. ${ }^{37}$ In the latter study patients with chest pain during exercise testing were investigated, but pain did not correlate with signs of myocardial ischaemia. Because there may be several causes of chest pain, further investigation of the exact nature of the pain would be required to confirm its relation to myocardial ischaemia. Exercise testing was not carried out in the present study; therefore assessment of symptoms was solely based on the patients' reports.

Patients with higher preoperative SF-36 scores in the domains of energy/vitality, mental health, and physical role limitation (that is, people who reported better levels of health) were more likely to have their breathlessness eliminated after CABG (table 4). By contrast, current smokers, younger patients, and those with lower levels of social support networks were significantly more likely to have postoperative breathlessness. This may be helpful 
information in terms of selection of patients for operation, as poorer outcomes in terms of cardiac events have been reported in smokers, ${ }^{38}$ individuals with diabetes mellitus, ${ }^{39}$ and in those with lower levels of social support networks. ${ }^{40}$ If breathlessness was present after CABG, then patients with high scores in bodily pain, energy and vitality, and social function at baseline assessment were likely to experience the greatest relief of breathlessness. Better health (as measured by five domains of the SF-36 questionnaire), older patients, not smoking, absence of diabetes mellitus, and higher levels of social support before operation were all associated with a better outcome in terms in relief of breathlessness.

The results of the multiple linear regression analysis indicated that the presence of postoperative angina was reduced in older patients and in those with higher preoperative bodily pain. Breathlessness was generally worse in patients with diabetes mellitus, but was improved for patients with high preoperative social network and mental health scores. The remaining variation in the scores is attributable to unidentified factors and to the random nature of the variables measured. The magnitude of the contribution of the preoperative variables observed in this study can be considered as significant in the context of the large range of possible influential factors in a clinical situation of such complexity. ${ }^{23}$

\section{LIMITATIONS}

Breathlessness may originate from other pathologies such as chronic obstructive airways disease, and additional investigations would be required to establish that symptoms were directly related to myocardial ischaemia. This is also the case for patient reports of angina. The patients in this study were younger than in local and national datasets, so the extent to which the finding can be generalised to all patients undergoing CABG may be questioned. A limitation of the study was the absence of any objective assessment of the origin of the symptoms reported by the patient, such as exercise tolerance testing or radioisotope imaging studies. This would be important to confirm that the symptoms experienced were a result of myocardial ischaemia. However, patient accounts of the severity of coronary artery disease symptoms are an important measure of severity of disease in terms of clinical management, and represent a critical factor in the use of health services and in care decision making. In addition, no account was taken of the details of the CABG surgical procedure undertaken other than number of grafts, or of angiographic documentation of disease severity and ventricular function. These factors may vary considerably within the patient group and have a significant effect on outcome.

\section{CONCLUSIONS}

The patients in our study reported more angina and breathlessness over one year following CABG surgery than in other previously published studies dealing with sympto- matic outcome. Patient's perceptions of their health status and levels of social support preoperatively were useful indicators of health status postoperatively. The baseline health status of patients may help to explain the variability in patient outcome in addition to the known clinical variables. Insight into the particular dimensions of health that were influential was also provided. These indices may be helpful in addition to other clinical factors in identifying high risk patients. Furthermore, interventions to improve levels of health and social support before surgery may improve symptomatic outcome.

We would like to thank the patients and their families who took part in this study, and Sister Ann Murray and staff, ward 65, Glasgow Royal Infirmary University NHS Trust. Our thanks are also due to P R Belcher FRCS and E W Muriithi FRCS, Department of Cardiac Surgery, University of Glasgow, for help and advice. This study was undertaken as a research training fellowship funded by the Chief Scientist Office, Scottish Office, Department of Health.

1 National Institutes of Health Consensus. Development Conference Statement: coronary artery bypass surgery: scintific and clinical aspects. N Engl F Med 1981;304:680-4.

2 Wheatley DJ. Coronary artery surgery: evolution, principles and applications. In: Wheatley DJ, ed. Surgery of coronary artery disease. London: Chapman and Hall, 1986.

3 Parsonnet V, Dean D, Bernstein AD. A method of uniform stratification of risk for evaluating the results of surgery in acquired heart disease. Circulation 1989;79:I3-12.

4 Cameron AA, Davis KB, Rogers WJ. Recurrence of angina after coronary artery bypass surgery: predictors and prognosis (CASS Registry). Coronary artery surgery study. f Am Coll Cardiol 1995;26:895-9.

5 McCarthy M, Shroyer AL, Sethi G, et al. Self-report measures for assessing treatment outcomes in cardiac surgery patients. Med Care 1995;33:OS76-85.

patients. Med Care 1995;33:OS76-85.
6 Wilkin D, Hallam L, Doggett M. Measurement of need and Wilkin D, Hallam L, Doggett M. Measurement of need and
outcome for primary health care. Oxford: Oxford University Press, 1992

7 Ware JE, Snow KK, Kosinski AS, et al. SF-36: health survey manual and interpretation guide. Boston: Nimrod Press, 1993

8 Stewart AL, Ware JE. Measuring functioning and wellbeing: the medical outcomes study. London: Duke University Press, 1992.

9 Jenkinson C, Coulter A, Wright L. Short form 36 (SF 36) health survey questionnaire: normative data for adults of working age. BMF 1993;306:1437-40.

10 Charlier L, Dutrannois J, Kaufman L. The SF-36 questionnaire: a convenient way to assess quality of life in
angina pectoris patients. Acta Cardiologica 1997;3:247-60.

11 House JS, Landis KR, Umberson D. Social relationships and health. Science 1988;241:540-5.

12 Berkman LF. The role of social relations in health Berkman LF. The role of social relation
promotion. Psychosom Res 1995;57:245-54.

13 Hemingway H, Marmot M. Psychosocial factors in the aetiology and prognosis of coronary heart disease: systematic review of prospective cohort studies. BMF 1999;318:14607.

14 Donald CA, Ware JE. The quantification of social contacts and resources. Santa Monica: Rand Corporation, 1982.

15 Kee KA, Kieckhefer GM. Measuring human responses using visual analogue scales. Western $\mathcal{F}$ Nurs Res 1989;11: 128-32.

16 Garratt AM, Ruta DA, Abdalla MI, et al. The SF-36 health survey questionnaire: an outcome measure suitable for routine use within the NHS? BMF 1993;306:1440-4.

17 Lohr KN, Brook RH, Kamberg CJ, et al. Use of medical care in the Rand Health Insurance experiment. Diagnosis- and service-specific analyses in a randomized controlled trial. Med Care 1986;24:S1-7.

18 Huskisson EC. Measurement of pain. Lancet 1974;ii:112731 .

19 McLoone P. Carstairs scores for Scottish postcode sectors from 1991 census. Glasgow: Public Health Research Unit, 1994

20 Sever P, Beevers G, Bulpitt C, et al. Management guidelines in essential hypertension: report of the second working party of the British Hypertension Society. BMF 1993;306: 983-7.

21 World Health Organisation. Measuring obesity: classification and description of anthropometric data. Nutr UD, EUR/ICP/ NUT, pp.125 Copenhagen: WHO, 1989

22 Report of the Great Britain and Ireland Cardiac Surgery Register. London: Society of Thoracic and Cardiovascular Surgeons of Great Britain and Ireland, 1996.

23 Wonnacott TH, Wonnacott RJ. Regression: a second course in statistics. New York: John Wiley \& Sons, 1981.

24 Orth-Gomer K, Johnson J. Social network interaction and mortality. A six year follow-up study of a random sample of the Swedish population. F Chron Dis 1987;40: 949-58. 
25 Kawachi I, Colditz GA, Ascherio A, et al. A prospective study of social networks in relation to total mortality and cardiovascular disease in men in the USA. $f$ Epidemiol Community Health 1996;50:245-51.

26 King KB, Reis HT, Porter LA, et al. Social support and long-term recovery from coronary artery surgery: effects on patients and spouses. Health Psychol 1993;12:1256-63.

27 Bucher HC. Social support and prognosis following first myocardial infarction. F Gen Intern Med 1994;9:409-17.

28 Grondin CM, Campeau L, Thornton JC, et al. Coronary artery bypass grafting with saphenous veins. Circulation 1989;79(suppl I):I124-9.

29 Lytle BW. The clinical impact of atherosclerotic saphenous vein to coronary artery bypass grafts. Semin Thorac Cardiovasc Surg 1994;6:81-6.

30 Wood D, Durrington P, Poulter N, et al. Joint British recommendations on prevention of coronary heart disease in clinical practice. Heart 1998;80 (suppl 2):S1-29.

31 Carstairs V, Morris R. Deprivation and health in Scotland. Aberdeen: Aberdeen University Press, 1991.

32 Morrison C, Woodward M, Leslie W, et al. Effect of socioeconomic group on incidence of, management of, and survival after myocardial infarction and coronary death: survival after myocardial infarction and coronary death:
analysis of community coronary event register. BMF 1997; analysis of
33 Pocock SJ, Henderson RA, Seed P, et al. Quality of life, employment status, and anginal symptoms after coronary angioplasty or bypass surgery. 3-year follow-up in the randomized intervention treatment of angina (RITA) trial. Circulation 1996;94:135-42.

34 Rumsfeld JS, MacWhinney M, McCarthy M, et al. Healthrelated quality of life as a predictor of mortality following coronary artery bypass graft surgery. FAMA 1999;281: 1298-303.

35 Lindsay GM, Hanlon P, Smith LN, et al. Eur f Cardiothorac Surg In press.

36 CABRI Trial Participants. First-year results of CABRI (coronary angioplasty vs bypass revascularisation investigation). Lancet 1995;346:1179-84.

37 Brandrup-Wognsen G, Haglid M, Karlsson T, et al. Preoperative risk indicators of death at an early and late reope after coronary artery bypass grafting. Thorac Cardiovas Surg 1995;43:77-82.

38 Herlitz J, Brandrup-Wognsen G, Haglid M, et al. Mortality and morbidity during a period of 2 years after coronary artery bypass surgery in patients with and without a history artery bypass surgery in patients with and without

39 Risum O, Abdelnoor M, Svennevig JL, et al. Diabetes mellitus Risum $\mathrm{O}$, Abdelnoor $\mathrm{M}$, Svennevig $\mathrm{JL}$, et al. Diabetes mellitus
and morbidity and mortality risks after coronary artery bypass surgery. Scand F Thorac Cardiovasc Surg 1996;30:71-5.

40 Berkman LF. The role of social relations in health promotion. Psychosom Res 1995;57:245-54.

\section{IMAGES IN CARDIOLOGY}

\section{Asymptomatic right atrial myxoma in acromegalic man: a case of Carney complex}

Carney complex is a rare familial multiple syndrome characterised by myxomas, endocrine overactivity, schwannomas, and spotty pigmented lesions on the skin. We report a case of a man with right atrial myxoma, acromegaly, multiple cystic skin lesions, and thyroid

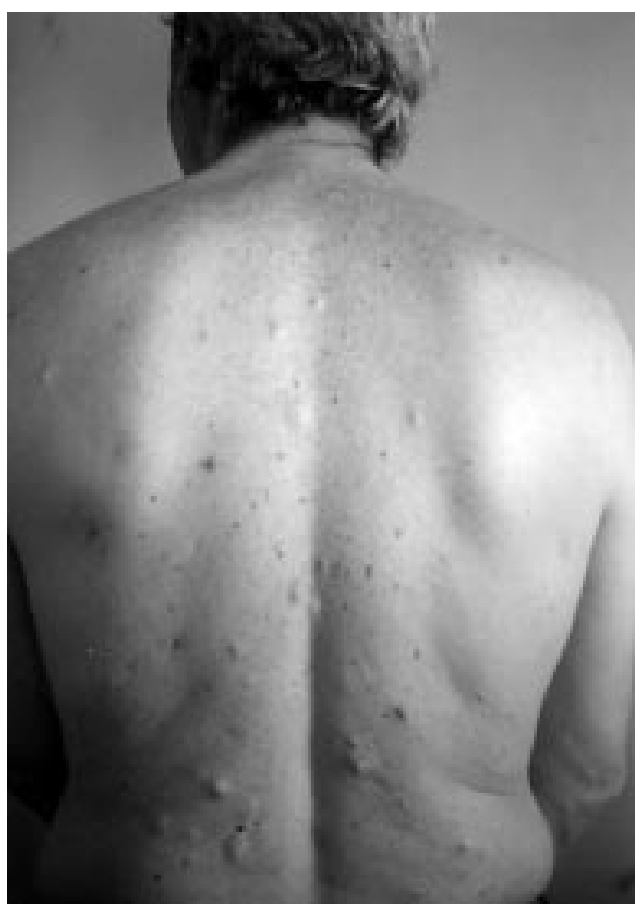

nodules. The Carney complex is a rare cause of right atrial myxoma.

Acromegaly and right atrial myxoma association is infrequent in this syndrome. We discovered myxoma in this patient only by following up the acromegaly. In fact, it developed asymptomatically. So it is very important in the patient with cardiac myxoma to investigate the presence of manifestations of endocrine overactivity and cutaneous lesions suggesting Carney complex.

GIANLUCA IACOBELLIS CIRA R T DI GIOIA GUIDO TAMBURRANO

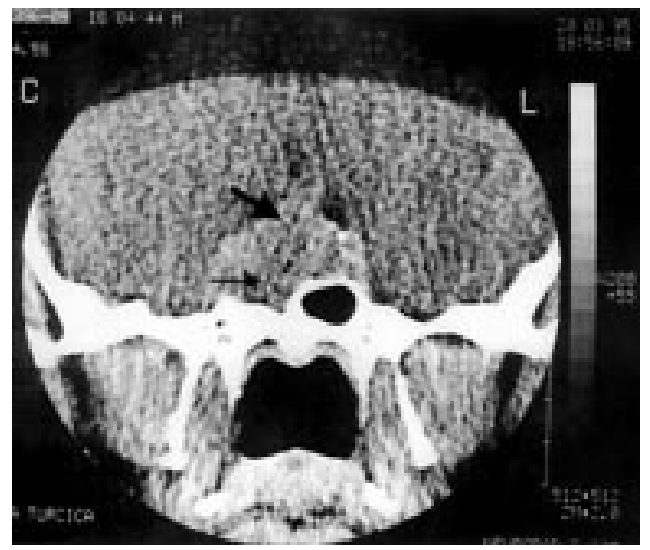

